\title{
POLÍTICAS DE IDENTIDADE E POLÍTICAS DE EDUCAÇÃO:
} ESTUDO SOBRE IDENTIDADE

\author{
POLÍTICAS DE IDENTIDAD Y DE EDUCACIÓN: ESTUDIO SOBRE \\ IDENTIDAD
}

IDENTITY POLICIES AND EDUCATION POLICIES: A STUDY ABOUT IDENTITY

http://dx.doi.org/10.1590/1807-0310/2017v29172186

Cecilia Pescatore Alves

Pontifícia Universidade Católica de São Paulo, São Paulo/SP, Brasil

\section{RESUMO}

Este estudo parte da psicologia social crítica e ressalta que a política educacional constitui uma política de identidade. Considerou-se que a escola se revela como uma instituição de socialização (em que se processam identidades) e um lugar em que ocorre a intersecção de várias culturas. Nesse contexto, consideraram-se como pilares fundamentais de reflexão um levantamento bibliográfico sobre as políticas públicas de educação vividas cotidianamente no contexto da instituição escolar e as concepções sobre o sintagma "Identidade-metamorfoseemancipação" e "políticas de identidade e identidades políticas". A discussão contemplou uma dimensão política da educação em um suporte epistemológico associado a um componente político-ético. O debate originou uma posição crítica de como a escola, enquanto instituição educativa, tem se posicionado com relação à constituição de identidades. Defende-se que as configurações do ideário neoliberal e as políticas impostas à educação impossibilitam ao indivíduo ações comunicativas na direção da emancipação.

Palavras-chave: políticas de identidade; políticas públicas de educação; identidades políticas.

\section{RESUMEN}

Este estudio surge de la psicología social crítica y resalta que la política educacional se constituye como una política de identidad. Se consideró que la escuela es una institución de socialización (donde se procesan identidades) y un lugar en el que ocurre la intersección de varias culturas. En este contexto se consideran como pilares fundamentales de reflexión: una literatura en las políticas públicas vividas cotidianamente en la institución escolar; las concepciones sobre sintagma-identidad-metamorfosis-emancipación; y políticas de identidad e identidades políticas. La discusión contempló la dimensión política de educación, con un soporte epistemológico asociado al componente político-ético. El debate origino una postura crítica de como la escuela, como institución educativa, se ha posicionado en relación a la formación de identidades. Se alega que las configuraciones neoliberalistas y las políticas impuestas a la educación impiden al individuo acciones comunicativas hacia la emancipación.

Palabras clave: políticas de identidad; políticas públicas de educación; identidades políticas.

\begin{abstract}
The present study starts from the critical social psychology and emphasizes that the educational policy constitutes as an identity policy. This study, had considered that school reveals itself as socializing institution (in which identities are processed) and a place in which the intersection of various cultures takes place. In this context, the fundamental pillars of reflectionare: a biographical survey about public education policies daily lived in the context of the school; the conceptions of the syntagma identity/metamorphosis/emancipation; identity policies and political identities. The discussion approached a political dimension of education in an epistemological support associated with a political/ethical component. The debate led to a critical position of how the school, as an educational institution, is positioning itself in relation to identity constitution. This paper also denounces that configurations of the neoliberal ideology and the policies imposed on education, make it impossible for the individual to take communicative actions in the direction of emancipation.
\end{abstract}

Keywords: identity policies; public education policies; political identities. 


\section{Introdução}

No Brasil, a Psicologia Social, na perspectiva de uma Psicologia Social Crítica, deu relevância ao estudo sobre a identidade humana a partir da concepção de que os fenômenos psicológicos são resultado de um processo de constituição social do indivíduo.

Nas palavras de Lane (1992a), essa "nova" Psicologia Social surge a partir da crise que se instalou por volta dos anos de 1970. Afirma a autora que, alinhada a pesquisadores da América Latina e Europa, buscou-se uma proposta teórico-metodológica a partir da postura materialista-histórica e dialética. Isto é, considerou-se que todos os fenômenos sociais e humanos são históricos e produzidos a partir da vida material, a qual se constitui em um processo de transformação constante, revelador de um movimento que tem por base a contradição.

A busca pela produção do conhecimento enquanto práxis comprometida com a realidade social direcionou o resgate de dois fatos que, na perspectiva de Lane (1992b), foi fundamental: que o ser humano só sobrevive em relação a outros da espécie inserido em um grupo social e, portanto, sua participação e ação dependem da linguagem.

Com esse intento, foi possível superar o modelo positivista de construir o conhecimento em psicologia social, mas fundamentalmente, ao transcender a dicotomia sujeito e objeto, produto e produtor, indivíduo e sociedade, o caminho trilhado passou a considerar o "ser humano como manifestação de uma totalidade histórico-social, produto e produtor da história" (Lane, 1992b, p. 32). Assim, para a Psicologia Social, a atividade constituiu-se como categoria de estudo do indivíduo, seguida pela consciência e personalidade.

Ciampa propunha ... demonstrar como as teorias de identidade desenvolvidas na ocasião, associadas inevitavelmente por interesses sociais, poderiam converter-se em formas de manipulação ideológica. $\mathrm{O}$ traço mais significativo da pesquisa estava no fato de assumir que a produção científica deve estar diretamente associada à práxis. (Lima \& Ciampa, 2012, p. 13)

As investigações de Ciampa e o conjunto de pesquisas desenvolvidas pela psicologia social levaram Lane (1995) a afirmar que algumas reformulações eram necessárias nas categorias fundamentais para a análise psicossocial. "Nossas investigações nos levaram, porém, a algumas reformulações. A primeira delas emergiu em várias pesquisas que apontavam para a identidade como uma categoria, a qual culminou com o estudo de Antonio C. Ciampa" (p. 56). A outra reformulação referida pela autora foi a inclusão da afetividade como uma categoria de análise. Assim, os fenômenos do psiquismo investigados passam a ser os subjetivos e as mediações que os constituem como processos; ao invés de se buscar sua estrutura, seus componentes e seus fatores determinantes, se delimitam campos de investigação a partir das categorias atividade, consciência, identidade e afetividade. Observa-se que a categoria "Personalidade" foi abandonada e substituída por "Identidade", e na sequência incluiu-se "Afetividade" como categoria de análise.

No âmbito dos indivíduos, a Consciência, a Atividade e a Afetividade constituídas pela mediação, não só da linguagem e do pensamento, mas também por emoções e afetos contraditórios entre o que se sente e o que se "deveria" sentir, levam tanto à fragmentação da consciência como da Atividade. (Lane, 1995, p. 62)

Os princípios, leis e categorias do materialismo histórico e dialético orientam concepções que procuram superar a dicotomia subjetividade-objetividade no estudo do indivíduo, abordando os processos psicológicos na sua constituição e produção a partir da atividade humana no contexto sócio-políticoeconômico. Essa concepção e um levantamento bibliográfico acerca das políticas públicas de educação, vividas cotidianamente no contexto da instituição escolar, norteará a reflexão sobre as possibilidades que a instituição escola reúne em torno do aluno na direção de uma identidade em emancipação.

\section{Política de Identidade e Identidade Política}

A proposta de que a identidade coletiva e a identidade individual sejam identidades sociais só é possível entendendo-as no processo de formação social, que se dá como metamorfose no movimento histórico em busca da emancipação. E é nesse contexto que se constitui o humano concreto em individualidades e coletividades, articulado com a história da sociedade e da natureza. Tal pressuposto se sustenta a partir do conceito de socialização, como na perspectiva de Berger e Luckmann (1973). Para os autores, a construção da realidade ocorre de forma objetiva e subjetiva e para compreendê-la é necessário considerar os aspectos em um processo dialético composto por três momentos: "exteriorização, objetivação e interiorização" (p.173) sem, contudo, pensá-los como que ocorrendo em uma sequência temporal.

No caso do indivíduo o mesmo se dá: ... simultaneamente exterioriza seu próprio ser no mundo 
e interioriza este último como realidade objetiva ... o indivíduo não nasce membro da sociedade. Nasce com "a predisposição para a sociabilidade e torna-se membro da sociedade" (Berger \& Luckmann, 1973, p. 173).

O processo de tornar-se membro da sociedade dialética é iniciado pela interiorização (a "base" que nos é imposta, coercitivamente) e, posteriormente, pela internalização, quando já conseguimos fazer escolhas por estarmos desenvolvendo uma relativa autonomia, gerando o processo de individuação.

Para Habermas (1983), o desenvolvimento de autonomia não é algo que se configura normalmente a partir da socialização, mas, sim, implica reinventar o desempenho dos papéis internalizados coercitivamente pelo processo de socialização. Desta feita, essa é uma possibilidade: isto é, mesmo se socializando e adquirindo a condição de indivíduo, nem todos conseguem adquirir uma crescente autonomia, permanecendo sempre muito dependentes.

Nesse sentido, afirmei em Alves (1997) que uma contradição se evidencia no processo de identidade na medida em que, diante da possibilidade de conquistar a condição de autor, de atribuir novos significados à identidade que nos é atribuída, reinterpretando os papéis sociais criativamente, podemos objetivamente reproduzir o determinado, o ditado socialmente por papéis cristalizados e previamente definidos.

A progressiva colonização do mundo da vida pela ordem sistêmica, seja pela economia (mercado), seja pelo poder (burocracia), gera situações de crescente heteronomia pessoal e ausência de fundamentação racional e intersubjetiva da normatividade social (Habermas, 1983). A busca de sentidos para a existência individual e para a vida em comum tornase uma necessidade prioritária na contemporaneidade. Nesse caminhar, estamos em processo permanente de metamorfose.

Nas palavras de Ciampa (1992), no presente se manifesta o passado enquanto história de vida e o futuro como projeto de vida. Compreender esse movimento constante requer um esforço em considerar criticamente a socialização, assim como o processo de individualização. Essas relações são discutidas por Ciampa (2002) a partir das noções de políticas de identidade e identidades políticas.

Afirma o autor que as políticas de identidade se revelam através das ações e ideologias dos grupos e coletividades (movimento feminista, movimento negro, movimento gay e muitos outros, bem como machismo, paternalismo, religiões, torcidas organizadas, etc.). As atividades por um lado buscam e/ou tentam conquistar ou manter uma hegemonia e por outro buscam e/ou lutam por emancipação.

Já as identidades políticas se referem à condição de sujeito e de autonomia - ou seja, pessoas que desenvolveram um pensamento próprio. Desenvolver autonomia implica uma identidade nomeada de "identidade do eu" que:

indica uma organização simbólica do Eu que, por um lado, reclama para si exemplaridade universal, sendo situada nas estruturas dos processos formativos em geral e tornando possíveis soluções ótimas para os problemas da ação, os quais reaparecem invariavelmente nas diversas culturas; e, por outro lado, uma organização autônoma do Eu não se instaura absolutamente de modo regular, quase como um resultado de processos naturais de amadurecimento, mas termina por ser, na maioria dos casos, um objetivo não alcançado. (Habermas, 1983, p. 50)

$\mathrm{Na}$ perspectiva do pensador, podemos pensar que a articulação entre políticas de identidade e identidades políticas, para a emancipação, ocorre na esfera da ação comunicativa do mundo da vida, constituído pelo espaço social no qual permite a realização da razão comunicativa. Essa, por sua vez, se dá sem coerção em contexto que prevalece o poder da solidariedade, já apontado por Marx (1996, 2004) nas relações de produção fundamentais na luta de classes. Diferentemente da ação estratégica e da razão instrumental, próprias da ordem sistêmica e fundamentais para o desenvolvimento das forças produtivas, desenvolvem mecanismos autorreguladores através dos subsistemas econômicos e políticos.

A partir desse campo de questionamento, configura-se a reflexão sobre políticas de identidade na busca por compreensão das possibilidades de libertação das coerções sociais, entendendo que essas não ocorrem na ausência de determinações, mas na busca de autodeterminação, aproximando-se do ser para si.

Libertar-se da coerção dos papéis para desempenhá-los à luz de princípios próprios é uma capacidade que surge ao indivíduo como possibilidade e não como inevitabilidade, mas no confronto dos contrários, no processo dialético da contradição, sempre no movimento da totalidade e das partes.

Esta condição crítica que possibilita a superação, Habermas (1983) já apontou, e teses desenvolvidas no Grupo Interdisciplinar de Pesquisa sobre Identidade Humana (PUCSP), coordenado por Ciampa, vêm identificando. Campos (2013), quando estuda o papel da tradição no processo de identidade, defende que "tradição pode conter a possibilidade da resistência, 
da produção de autonomia e de fragmentos de emancipação diante de um mundo cada vez mais dominado e disciplinado" (p. 202). Afirma ainda o autor que a tradição pode, contudo, "significar a reprodução da mesmice, da transformação da autonomia em heteronomia e da liberdade em dependência” (p. 202).

Em Souza (2007) também encontramos a defesa pela possibilidade de emancipação do ser humano. Ao estudar um projeto utópico na articulação com a história identifica, através da análise das histórias de vida de três educadoras de rua, possibilidades emancipatórias. Essas surgem na articulação entre o desejo utópico de construir o novo e as contradições próprias de cada história de vida. E é nesse estar sendo - na realidade cotidiana - que estas educadoras se instrumentalizam para reinventar a utopia e continuar investindo no novo.

Por sua vez, em pesquisa com mulher longeva, Gonçalves (2014) aponta que, ao longo da vida no confronto da opressão e das imposições sociais, a narradora revela que repensou a condição de subalternidade e rompeu com a opressão do ser feminino.

As teses aqui citadas manifestam diferentes situações reunidas em torno do sujeito que possibilitam o confronto para a superação da coerção. A essas condições nomeio políticas de identidade em direção à emancipação.

Caminho similar percorri em pesquisa com adolescentes (Alves, 1997) ao identificar, nas narrativas de histórias de vida e projetos de futuro de adolescentes, a família e a escola como mediadoras de políticas que possibilitam a emancipação (autonomia e princípios próprios) ou a colonização (manter a hegemonia). Tais formulações abrem espaço para a questão em curso: as relações vividas cotidianamente no contexto da instituição escolar possibilitam identidades em processo de emancipação? Ou ainda identidades políticas?

Para contextualizar o debate na realidade social, política e econômica, torna-se necessário discorrer sobre as implicações que a configuração da base infraestrutural da sociedade, promovida pela atual reorganização do capitalismo, fornece à formação da criança e do jovem. A presente questão adensa principalmente a discussão da atual situação educacional no Brasil e das possibilidades de constituição de identidades em emancipação a partir da compreensão de duas premissas que se relacionam dialeticamente: as transformações proporcionadas pela crise do capitalismo real - final do século XX no campo educativo - e o ideário neoliberal.
Sobre essa questão, afirma Frigotto (2010): “o neoliberalismo se põe como uma alternativa teórica, econômica, ideológica, ético-política e educativa à crise do capitalismo deste final de século" (p. 75).

Discute o autor que na concepção de Chauí a crise da razão no pós-modernismo ocorre no âmbito teórico e a partir da negação de quatro aspectos: a esfera da objetividade substituída pelo subjetivismo narcísico; a perspectiva do descontínuo em detrimento da continuidade temporal e o sentido da história; o micro poder disciplinando o social no lugar da estrutura das instituições; e ganha ênfase a diferença, a alteridade, a subjetividade e o privado sobre o público em detrimento das categorias gerais: universalidade, objetividade, ideologia e verdade.

Já no plano econômico, o ideário neoliberal, quando manifestado, ocorre em função da crise do padrão de acumulação e de regulação que sustentou a exploração capitalista nos últimos 50 anos: o "capitalismo denominado de bem-estar social" (Frigotto, 2010, p. 77). Lembra-nos, ainda, o autor que, de acordo com Eric Hobsbawm, a transnacionalização do capital e a hegemonia do capital financeiro - o capitalismo do bem-estar social - acaba implodindo juntamente com a referência do "Estado-nação".

Em decorrência, ocorre a recomposição econômica e a radicalização do neoconservadorismo, e o mercado adquire condição de sujeito e se constitui no regulador das relações sociais. E é nesse contexto que a resposta neoliberal prioriza a acumulação de capital, a partir da qual a distribuição se realizaria segundo as leis do mercado.

A educação, na lógica do capital, consiste em inserir os indivíduos no mercado de trabalho por meio do desenvolvimento de competências e habilidades. Afirma ainda Frigotto (2010) que categorias como qualidade, competência e cidadania têm seus sentidos ressignificados, isto é, marcados pelo individualismo e pela competitividade.

Outro plano importante que sustenta as transformações neoliberais, na concepção do referido autor, é o ideológico. Se fomentada a crença de que a crise é passageira e conjuntural, e que a única forma de relação é a capitalista, assim como o setor público é ineficiente, possibilita a tese do Estado mínimo. Não se pode deixar de destacar o monopólio da informação e a proposta em curso da privatização.

Finalmente, cabe ênfase à naturalização da exclusão e às diferentes formas de violência como o extermínio de grupos e populações. Assim, se inicia o século XXI e sedimentam-se as crises no plano econômico, teórico, ético-político e ideológico. 
Acrescenta-se ao debate a forma como a educação foi sendo tecida e/ou (des) considerada ao longo da história brasileira pelo poder público. Esse contexto se articula com as reflexões relativas às políticas de identidade que se manifestam no contexto escolar na medida em que dados de pesquisas desenvolvidas por Alves, Souza, Silva e Oliveira (2014) possibilitam identificar que: (a) o projeto de educação, tecido ao longo da história brasileira, tem sustentado a instituição escolar como mediadora de uma política de identidade que prioriza a colonização em detrimento da emancipação; (b) o século vigente foi inaugurado com novas definições de políticas educacionais cujos projetos de ensino não possuem significado que mobilize ações transformadoras na medida em que os fins são extrínsecos e retroalimentados por uma rede que envolve estratégias governamentais de desenvolvimento, como os meios de comunicação de massa, as agências internacionais e o mercado econômico; (c) as transformações sociais, ocorridas na década de 1990, decorrentes da internacionalização da economia (a chamada globalização) têm afetado a educação escolar, gerando contextos diversificados de relações. Autores como Touraine (1999), Gentili (2001), Bianchetti (2001), entre outros, analisaram nos anos de 1990 o impacto dessas transformações na educação em um plano de abordagem macroeconômica, considerando os problemas educacionais como decorrentes do reordenamento institucional promovido no âmbito das mudanças estruturais em desenvolvimento.

Cabe destaque que, no campo educativo, chegam ao Brasil, em 2016, novos ajustes neoliberais, já implantados nos anos 1980. Apropriam-se da ideia de "escola pública, gratuita e de qualidade", mas o que se apresenta são políticas de inclusão/exclusão através do aniquilamento da escola pública e o surgimento de escolas cooperativas, sistemas escolares de empresas, adoção de escolas públicas e escolas organizadas por comunidades. O que hoje temos, por exemplo, são algumas escolas oficialmente passadas para a Secretaria de Segurança Pública (foram militarizadas em Goiás) e em São Paulo as Escolas Técnicas da Secretaria de Educação passaram para Secretaria de Ciência e Tecnologia.

Dando continuidade a essa política de sucateamento da escola pública, ocorre a reforma do ensino médio com ênfase na diversificação de trajetórias para os alunos. Através de medida provisória, a presidência da República institui a Política de Fomento à Implementação de Escolas de Ensino Médio em Tempo Integral. A medida altera a Lei $\mathrm{n}^{\circ}$ 9.394, de 20 de dezembro de 1996, que estabelece as diretrizes e bases da educação nacional, e a Lei $\mathrm{n}^{\circ}$ 11.494, de 20 de junho 2007, que regulamenta o Fundo de Manutenção e Desenvolvimento da Educação Básica e de Valorização dos Profissionais da Educação e dá outras providências. Promove ampliação da carga horária e a implementação de tempo integral para o ensino médio. No que se refere à grade curricular, torna obrigatório nos três anos o ensino de língua portuguesa e matemática. Contudo, o ensino da arte e da educação física é facultativo (Medida Provisória n. 746, 2016).

O currículo do ensino médio será composto pela Base Nacional Comum Curricular (BNCC) e por itinerários formativos específicos definidos em cada sistema de ensino e com ênfase nas áreas de linguagens, matemática, ciências da natureza, ciências humanas e formação técnica e profissional. Dá autonomia aos sistemas de ensino para definir a organização das áreas de conhecimento, as competências, habilidades e expectativas de aprendizagem definidas na BNCC (Medida Provisória n. 746, 2016).

Observa-se que a política é clara nos objetivos de ajustes neoliberais, já mencionados neste ensaio. A explicação sobre a ementa contida no site do Senado esclarece que a reforma "marca o encontro do Brasil com as demandas da economia e abre espaço tanto para decisiva contribuição do 'Sistema S' quanto para aliviar a crise financeira dos Estados" (Medida Provisória n. 746, 2016).

Cabe esclarecer que o termo "Sistema S" define o conjunto de organizações das entidades corporativas voltadas para o treinamento profissional, assistência social, consultoria, pesquisa e assistência técnica que, além de terem seu nome iniciado com a letra $\mathrm{S}$, têm raízes comuns e características organizacionais similares. Fazem parte do Sistema S: o Serviço Nacional de aprendizagem Industrial (SENAI); o Serviço Social do Comércio (SESC); o Serviço Social da Indústria (SESI); e o Serviço Nacional de Aprendizagem do Comércio (SENAC). Existem ainda os seguintes: Serviço Nacional de Aprendizagem Rural (SENAR); Serviço Nacional de Aprendizagem do Cooperativismo (SESCOOP); e Serviço Social de Transporte (SEST) (Senado Federal, 2017).

Tal formulação sustenta a lógica de privatização e tecnicismo do ensino ao conclamar as organizações corporativas para a responsabilidade junto ao processo de renovação do ensino médio.

E mais: toma corpo e entra em debate a proposta - que de longa data já assolava a sociedade - da escola sem partido, preconizando a neutralidade do conhecimento. A proposta dispõe sobre a inclusão, 
entre as diretrizes e bases da educação nacional de que trata a Lei $\mathrm{n}^{\circ}$ 9.394, de 20 de dezembro de 1996, de itens como: "Art. $2^{\circ}$. A educação nacional atenderá aos seguintes princípios: I - neutralidade política, ideológica e religiosa do Estado" (Malta, 2016).

Pressupor que a formação da criança e do jovem possa ser neutra ideológica, religiosa e politicamente é negar a concepção de que a constituição do sujeito ocorre na dinâmica do processo social, no confronto com o outro e com a diversidade.

\section{Políticas de identidade e Políticas públicas educacionais - o significado político da escola}

A criança é formada para ter certos comportamentos sociais e ocupar certo lugar na sociedade, em classes em que cada um ocupa o papel destinado à sua divisão social do trabalho. A aquisição de papéis sociais pressupõe a internalização de valores e regras. Tudo isso revela ideologias. Negá-las é reproduzir a ideologia dominante de forma coercitiva.

Por sua vez, os pais se interessam pela função real da educação: futuro social e profissional de seus filhos. No entanto, se essa função da educação se constitui como o desejado pelas famílias, não podemos negar a necessidade de cada cidadão se inserir na sociedade. Mesmo assim, carece da necessidade de uma formação que possibilite transformações autônomas em detrimento de heteronomias coercitivas.

Para essas considerações me inspiro em Severino (1997) quando postula que o ensino no processo de formação profissional remete à reflexão sobre a importância do saber para a existência humana. Não podemos falar sobre a existência humana excluindo a contínua contribuição do conhecimento e, ainda, que essa existência é histórica e o sujeito histórico necessariamente é coletivo.

Só se é algo mediante um contínuo processo do agir, da ação. A consciência, o pensamento, enquanto equipamento da subjetividade humana, nasceu embutido na própria prática do homem, originariamente na sua prática produtiva, pela qual dava conta de sua existência material. Por isso, a esfera básica da existência humana é aquela do trabalho propriamente dito, ou seja, prática que alicerça a existência material dos homens, já que a vida depende radicalmente dessa troca entre o organismo e a natureza física. Essa esfera da prática produtiva constitui o universo do fazer (Severino, 1997).

A prática produtiva dos homens - protagoniza ainda o autor - não se dá como trabalho individual, antropologicamente falando; é expressão de um sujeito coletivo. A espécie humana só é humana na medida em que se efetiva em sociedade. Não se trata, contudo, de uma coletividade gregária, mas a sociedade humana é peculiar: os sujeitos individuais não se justapõem, uns ao lado dos outros, em condições de simétrica igualdade, mas se colocam hierarquicamente, uns sobre os outros, uns dominando os outros. Torna-se uma sociedade política, o que caracteriza nossa prática social envolvendo-os na esfera do poder.

Portanto, temos a prática produtiva e a prática política que são atravessadas pela prática simbolizadora. Isto é, o conhecimento individual se dá sobre um fundo de uma experiência radicalmente histórica e coletiva que lhe é anterior e que o nutre. Um contexto complexo que vai se construindo pela contínua articulação de novas experiências, já tornadas possíveis pelas experiências passadas e acumuladas a cultura - o universo do saber.

A prática real da constituição da existência humana é histórica e socialmente construída a partir do exercício de práticas produtivas, práticas políticas e práticas culturais. A presença da atuação do poder nas relações entre os homens se constitui como verdade.

Assim sendo, a adoção de propostas distintas de regime escolarpara sujeitos de classes pobres, sobretudo no sistema educacional público; a mudança do discurso oficial sobre as políticas educacionais; a introdução de mecanismos avaliativos do sistema educacional, baseados na produtividade (desenvolvimento de competências e habilidades), através da definição das prioridades de investimento; o crescente processo de exclusão social; as transformações no estatuto do sujeito contemporâneo; a ruptura ou a dissolução do papel mediador da escola no processo de socialização, entre outras, são algumas consequências da interferência de agências multilaterais internacionais na organização e estruturação dos sistemas escolares nacionais.

Por outro lado, "a crise educacional resulta, em primeiro lugar, da falência dos poderes públicos em propor políticas educacionais direcionadas aos interesses públicos e, em segundo, das características mercantis da cultura hegemônica" (Alves et al., 2014, p. 191).

Ao discutir a relação de cultura e escola, os referidos autores retomam o debate realizado por Williams (2000) e já apontado por autores como Bourdieu e Passeron (1982) sobre a função da escola enquanto campo privilegiado de reprodução cultural: “em geral, pode-se dizer que está implícito no conceito de cultura ser ela capaz de ser reproduzida e, além 
disso, que em muitos de seus aspectos, a cultura é, na verdade, um modo de reprodução" (p. 193).

Nas postulações de Charlot (2013), o significado político da escola justifica-se na medida em que ela é considerada uma instituição social e, portanto, transmite os modelos sociais, difunde ideias políticas e forma o sujeito.

Diferentemente das proposições em que se supõe a neutralidade da escola sob a pretensa neutralidade do conhecimento, defendemos que a instituição escolar, ao negar uma posição ideológica, oculta o significado político da educação. Essa prática pedagógica possibilita políticas de identidade em que o confronto é aniquilado, ao não possibilitar que o diálogo adquira características de comunicação crítica. Dessa forma, a criança e o adolescente que vivem a vida cotidiana no interior das escolas, ao se transformarem, pelo processo de metamorfose, continuam presos aos papéis cristalizados socialmente.

As políticas públicas de educação, ao considerarem que a situação social do indivíduo é consequência da sua formação cultural e que ele pode concebê-las sem referência direta às realidades sociais, atribuem um sentido cultural à educação e mascaram ideologicamente seu significado político e de classe, impossibilitando compreender que a cultura do indivíduo é determinada pelas realidades econômicas, sociais e políticas.

E o que se evidencia no cotidiano das instituições de ensino é a redução do problema social da educação ao da cultura individual. Ser reconhecido implica certas aptidões, virtudes e capacidades individuais, impostas pela cultura elitista. Caso isso não ocorra, o aluno é tratado como desvio.

A concepção de cultura comum de Williams (2000) faz oposição ao conceito fragmentado de cultura como "alta cultura", "cultura de massa" e "cultura técnica" e denuncia a hegemonia cultural como um processo de relações que reafirma a escola como locus de formação para o mercado de trabalho. Para o pensador britânico, a noção de cultura comum no cotidiano escolar contempla o respeito à cultura produzida pelo aluno e pelo grupo do qual se originou, assim como disponibiliza a fruição de outros conhecimentos e de outras produções culturais. Contemplar a diversidade cultural - em contraste com a monocultura utilitarista - não significa que a escola deva se eximir de sua responsabilidade com relação à produção das coisas no mundo. Pelo contrário, a escola pode aparecer como local onde se encontra e se produz o conhecimento, mas, fundamentalmente, que esse é posse daqueles que vivem a experiência e podem compartilhá-la.

\section{Considerações finais}

Refletir sobre Políticas de Identidade e Políticas Públicas de Educação a partir dos caminhos norteados pela psicologia social crítica no seu processo de constituição enquanto área do saber científico, comprometido com a realidade social e com a construção de um conhecimento pela emancipação humana, exigiu, necessariamente, contemplar nessa discussão uma dimensão política, em um suporte epistemológico associado a um componente políticoético. Sobretudo foi fundamental considerar uma ética social fundamentada na noção de cidadania plena para todos e cuja validade epistêmica ocorre a partir da não neutralidade do conhecimento, da não adequação às condições de vida, da não discriminação a qualquer diferença e à clareza dos pressupostos da concepção de homem e de indivíduo que possibilitem a busca para a emancipação.

Tal alternativa deslocou o debate para o campo da política, reafirmando a necessidade da escola ser considerada como espaço de educação formal cujo caráter político não é negado. Sob o manto da neutralidade, as instituições educativas assumem um empreendimento de formação de crianças que, segundo Charlot (2013), tem um duplo objetivo: formar o indivíduo e possibilitar a integração social.

Ora, desde a sua origem, a Psicologia Social Crítica constata que a relação do indivíduo com a sociedade ocorre de forma dialética, derivando dessa relação a identidade humana. Essa constatação possibilitou a pesquisa sobre identidade e suas relações com a ideologia. Nesse sentido, afirma Ciampa (2002) que o estudo sobre identidade transcende uma questão científica e passa a ser uma questão política fundamentalmente. Portanto, refletir sobre a identidade humana a partir do sintagma identidade-metamorfose-emancipação frente às políticas públicas de educação possibilitou uma posição crítica perante a atuação da escola, enquanto instituição educativa, no que se refere ao seu posicionamento com relação à constituição de identidades.

Habermas (1983) afirma que a instituição é o lugar onde a unidade e a multiplicidade se constroem mutuamente, mas que este movimento tende a ser abafado na sociedade moderna, e os papéis tendem a se tornar complexos de comportamentos cristalizados e estereotipados. Ao invés de permitirem o exercício profissional e relacional, tornam-se marcas, estigmas, e as pessoas passam a ser não para si e para o outro, mas para o seu papel e para sua instituição. 
As análises aqui iniciadas sobre a escola atual brasileira identificam que as configurações do ideário neoliberal e as políticas impostas à educação estão privando a criança e o jovem da aquisição do conhecimento a partir de ações comunicativas. A articulação entre políticas de identidade e identidades políticas, para emancipação, precisa ocorrer na esfera da ação comunicativa do mundo da vida, na qual prevalece o poder da solidariedade - diferentemente da ação estratégica e da ação instrumental, próprias do sistema, quando prevalece o poder do dinheiro (mercado) e o poder da burocracia (capital) - na tentativa de não sucumbirmos às condições de meros atores, para os quais passam despercebidas as contradições que as relações do mundo global possam estar tecendo.

Enfim, diante dos paradoxos produzidos nas relações efetivadas no interior da escola e as possibilidades de identidades em emancipação, cada vez mais se revela a necessidade da escola redefinir seu papel, objetivos e limites. Cabe à instituição escolar possibilitar uma ação reflexiva sobre a penetração da racionalidade instrumental e dos mecanismos de integração do dinheiro e do poder no seu interior, a fim de caminharmos para o desenvolvimento enquanto ser humano pleno em direção à emancipação.

A renovação do sistema escolar não é uma questão apenas de currículo, ou mesmo de competência, mas, sim, de mudanças ideológicas e estruturais que ampliem as reflexões sobre o seu significado na constituição da identidade humana e gerem políticas de identidade que possibilitem identidades políticas.

\section{Referências}

Alves, C. P. (1997). "Eu nunca vou parar de buscar nada". Emancipação frente à colonização e as políticas de identidade na adolescência. Tese Doutorado, Programa de Pós-graduação em Psicologia Social, Pontifícia Universidade Católica de São Paulo, SP.

Alves, C. P., Souza, R. T., Silva, A. L., \& Oliveira, W. J. (2014). Apontamentos sobre políticas públicas de educação e dinâmica cultural. Revista Brasileira de Gestão e Desenvolvimento Regional, 10(3), 185-205. Recuperado de http://www.rbgdr.net/revista/index.php/rbgdr/article/ view/1477/400

Berger, L. P. \& Luckmann, T. A. (1973). A construção social da realidade. Petrópolis, RJ: Vozes.

Bianchetti, R. G. (2001). Modelo neoliberal e políticas educacionais ( $3^{\mathrm{a}}$ ed.). São Paulo: Cortez.

Bourdieu, P. \& Passeron, J. C. (1982). A reprodução: elementos para uma teoria do sistema de ensino. Rio de Janeiro: Francisco Alves.

Campos, A. O. (2013). Sobre a tradição e sua apropriação crítica: metamorfoses de uma afroamericalatinidade em luta. Tese de Doutorado, Programa de Pós-graduação em
Psicologia Social, Pontifícia Universidade Católica de São Paulo, SP.

Charlot, B. (2013). A mistificação pedagógica: realidades sociais e processos ideológicos na teoria da educação. São Paulo: Cortez.

Ciampa, A. C. (1992). A estória do Severino e a história da Severina: um ensaio de Psicologia Social. São Paulo: Brasiliense.

Ciampa, A. C. (2002). Políticas de identidade e identidades políticas. In C. I. L. Dunker \& M. C. Passos (Orgs.), Uma Psicologia que se interroga: ensaios (pp. 133-144). São Paulo: Edicon.

Frigotto. G. (2010). Os delírios da razão-crise do capital e metamorfose conceitual no campo educacional. In P. Gentili (Org.), Pedagogia da exclusão: crítica ao neoliberalismo em educação (15 ed., pp. 73-102). Petrópolis, RJ: Vozes.

Gentili, P. (Org.). (2001). Pedagogia da exclusão: crítica ao neoliberalismo em educação ( 8 a ed.). Petrópolis, RJ: Vozes.

Gonçalves, A. A. F. (2014). De oprimida e explorada a liberta e autônoma: o empoderamento feminino desvendado pelo universo da mulher longeva. Tese de Doutorado, Programa Pós-graduação em Psicologia Social, Pontifícia Universidade Católica de São Paulo, SP.

Habermas J. (1983). Para a reconstrução do materialismo histórico. São Paulo: Brasiliense.

Lane, S. T. M. (1992a). A Psicologia Social e uma nova concepção de homem para a Psicologia. In S. T. M. Lane \& W. Codo (Orgs.), Psicologia Social: o homem em movimento (10 ed., pp. 10-19). São Paulo: Brasiliense.

Lane, S. T. M. (1992b). Linguagem, pensamento e representações sociais. In S. T. M. Lane \& W. Codo (Orgs.), Psicologia Social: o homem em movimento $\left(10^{\mathrm{a}}\right.$ ed., pp. 3239). São Paulo: Brasiliense.

Lane, S. T. M. (1995). A mediação social na constituição do psiquismo humano. In S. T. M. Lane \& B. B. Sawaia (Orgs.), Novas veredas da psicologia social (pp. 55-63). São Paulo: Brasiliense; Educ.

Lima, A. F. \& Ciampa, A. C. (2012). Metamorfose humana em busca de emancipação: a identidade na perspectiva da Psicologia Social crítica. In A. F. Lima (Org.), Psicologia Social crítica. paralaxes do contemporâneo (pp. 11-29). Porto Alegre: Sulina.

Malta, M. (2016). Projeto de Lei do Senado $n^{\circ} 193$. Programa Escola Sem Partido. Brasília, DF: Senado Federal. Recuperado de http://www25.senado.leg.br/web/atividade/ materias/-/materia/125666

Marx, K. (1996). Manifesto do Partido Comunista (6 $6^{\mathbf{a}}$ ed.). Petrópolis, RJ: Vozes.

Marx, K. (2004). O Capital: crítica da economia política (Vol. II, 22a ed.). Rio de Janeiro: Civilização Brasileira.

Medida Provisória n. 746, de 22 de setembro de 2016. (2016). Institui a Política de Fomento à Implementação de Escolas de Ensino Médio em Tempo Integral. Brasília, DF: Presidência da República. Recuperado de http://www25.senado.leg.br/ web/atividade/materias/-/materia/126992

Senado Federal. (2016). Sistema S. Recuperado de http:// www12.senado.leg.br/noticias/glossario-legislativo/ sistema-s

Severino, A. J. (1997). Filosofia e Ciências Humanas no ensino de $2^{\mathrm{a}}$ Grau: uma abordagem antropológica da formação dos adolescentes. In J. J. Queiroz (Org.), Educação hoje: tensões e polaridades (pp. 101-109). São Paulo: FECS; USF. 
Souza, A. M. M. (2007). Entre a história e a utopia: o educador de rua do projeto Axé. Tese de Doutorado, Programa de Pósgraduação em Psicologia Social, Pontifícia Universidade Católica de São Paulo, SP.

Touraine, A. (1999). Podemos viver juntos? Iguais e diferentes. Petrópolis, RJ: Vozes.

Submissão em: 18/11/2016

Revisão em: 05/01/2017

Aceite em: 25/06/2017

Cecilia Pescatore Alves é psicóloga, mestre e doutora em Psicologia Social. Professora aposentada da Universidade de Taubaté. Professora doutora da Pontifícia Universidade Católica de São Paulo.

Endereço: Faculdade de Ciências Humana e da Saúde, Psicologia - PUC/SP. Rua Monte Alegre, 984, Perdizes, São Paulo/SP, CEP 05014-901.

E-mail: cpescatore@uol.com.br 